\title{
Decompositions of Cationized Heterodimers of Amino Acids in Relation to Charge Location in Peptide Ions
}

\author{
Odile Burlet and Simon J. Gaskell \\ Center for Experimental Therapeutics, Baylor College of Medicine, and Department of Chemistry, University \\ of Houston, Houston, Texas, USA
}

\begin{abstract}
The unimolecular decompositions of protonated heterodimers of native and derivatized amino acids to yield the protonated monomers were studied as a guide to charge location in peptide ions. Analyses using a hybrid instrument of $\mathrm{BEqQ}$ geometry demonstrated the advantages (with respect to mass resolution, sensitivity, reproducibility, and the elimination of extraneous signals) of the detection of product ions formed in the radiofrequency-only quadrupole region (q) rather than in the field-free region between $B$ and $E$. Conversion of arginine to dimethylpyrimidylomithine (DMPO) reduced the proton affinity, as evidenced by the decomposition of the protonated arginine/DMPO heterodimer. Conversion of cysteine to pyridylethylcysteine enhanced the proton affinity. Application of these derivatization procedures to peptides resulted in changes in the observed fragmentations of the protonated precursors consistent with the predicted modifications in charge location. Unimolecular decomposition of the protonated dimer composed of glycine and $\mathrm{N}$-acetylglycine yielded both protonated monomers with abundances differing by a factor of only 2; this suggests that in protonated peptides, the amide bonds are competitive with the $\mathrm{N}$-terminal amino group as sites of protonation. It is clear that the propensities to proton or metal-cation location at particular sites in peptides are influenced by both short- and long-range intraionic interactions. In peptides composed of amino acids of similar cation affinities, it may be postulated that the ion population is heterogeneous with respect to the site of charge, with consequent promotion of multiple low-energy fragmentation routes. (/ Am Soc Mass Spectrom 1993, 4, 461-469)
\end{abstract}

$\mathrm{T}$ landem mass spectrometry with collision-activated decomposition (CAD) of precursor ions is widely used for the determination of peptide sequences. When collisions involve high kinetic energy precursor ions (the conditions that generally apply to analyses performed on sector instruments), the fragmentations observed include processes that necessarily occur remote from the site of charge, together with others that may also be interpreted as charge remote [1]. In these instances, the site of charge is important in determining which of the complementary fragments is detected. Evidence for the occurrence of charge-remote processes is based on the observation of fragmentations of protonated peptides containing strongly basic residues (especially arginine) and of peptides carrying a fixed charge (such as a quaternary ammonium or other derivative group) [1-4].

Under low-energy CAD conditions, such as apply when a radiofrequency-only quadrupole is used as the

Address reprint requests to Simon J. Gaskell, Department of Chemistry, UMIST, Manchester M60 1QD, U.K. decomposition region, charge-directed fragmentation appears to predominate. The formation of sequence ions of the $Y_{n}^{\prime \prime}$ and $B_{n}$ types [5], for example, is considered to result from protonation of the amide bond [6]. The distribution of charge between complementary $Y_{n}^{\prime r}$ and $B_{n}$ ions is then influenced by the energetics of the collision process and by the relative gas-phase basicities of the two fragments [6]. Specific evidence for the influence of charge localization on the low-energy fragmentation of protonated peptides was provided by our recent study of C-terminal arginyl peptides containing a cysteine or cysteic acid residue [7]. A comparison of the low-energy fragmentations of the protonated peptides showed a promotion of the $Y_{n}^{\prime \prime}$ series of product ions and markedly higher fragmentation yield for the cysteic acid-containing analogues. The evidence indicated an intraionic interaction between the cysteic acid and the arginine side chains. It was suggested that this resulted in a reduced prevalence of protonation on the arginine side chain. The increased heterogeneity of the precursor ion population with respect to site of protonation was proposed to result in a multiplicity of possible charge-directed fragmentations. 
The fragmentation properties of peptide ions may be influenced by appropriate derivatization of functional groups. In the above-mentioned study of the apparent interaction of the arginine and cysteic acid side chains, for example, the effect was attenuated by the conversion of the arginine residue to dimethylpyrimidylornithine (DMPO). Whereas this observation was most plausibly attributed to differences in basicity between the arginine and DMPO residues, the possibility of a purely stereochemical effect suggested the value of a direct comparison of proton affinities.

Derivatization strategies may also be adopted in the mass spectrometric analyses of peptides for reasons other than the explicit intention to modify fragmentation properties. Esterification, for instance, has been used to increase the hydrophobicity of peptide ions and, consequently, to improve their detection in conventional fast-atom bombardment (FAB) spectra [8]. $N$-acetylation has been used to identify N-terminal fragments $[9,10]$. This "labeling" approach may, however, result in modification of the charge-site distribution in peptide ions, with consequent effects on the fragments observed. Further justifications for the derivatization of peptides may be unrelated to the mass spectrometric analysis. For instance, pyridylethylation and carboxymethylation of cysteine residues are often used in protein analyses to stabilize cysteine residues and to differentiate them from disulfidebridged cystine residues.

The CAD of peptides complexed with alkali metal ions (especially $\mathrm{Na}^{+}$and $\mathrm{Li}^{+}$) has been interpreted in terms of the location of the cation on the peptide. Various binding sites have been proposed to explain the fragment ions observed. Gross and co-workers [11, 12] and Leary et al. [13] have envisaged a lithiated peptide as the protonated lithium salt of the C-terminal carboxyl moiety. In contrast, bidentate chelations have been proposed for the interaction of alkali metal ions with various peptides $[14-18]$. Specific interactions between metal cations and amino acid side chains were observed with basic amino acids [12].

Full elucidation of the mechanisms of low-energy fragmentations of protonated and metal-cationized peptides requires an understanding of the likely sites of protonation and cationization. Similarly, understanding of the effects of derivatization (chemical and steric) on the fragmentation properties of the peptides requires knowledge of the probable charge site. In the present work, the decompositions of cationized heterodimers of native and derivatized amino acids were examined as a guide to the relative significance of different cation locations in peptide ions. This experimental approach was taken by Bojesen [19] and more recently by others $[20,21]$ to estimate the gas-phase proton affinities of the $20 \mathrm{~L}$-amino acids. The principle of the method was established by Cooks and Kruger [22]. The approach is based on the rate of competitive reactions observed during the unimolecular dissociation of a protonated dimer composed of two bases (eq 1):

$$
\begin{aligned}
{\left[\mathrm{B}_{1} \cdot \mathrm{B}_{2}+\mathrm{H}\right]^{+} } & \stackrel{\mathrm{k}_{1}}{\rightarrow}\left[\mathrm{B}_{1}+\mathrm{H}\right]^{+} \\
& \stackrel{\mathrm{k}_{2}}{\rightarrow}\left[\mathrm{B}_{2}+\mathrm{H}\right]^{+}
\end{aligned}
$$

The ratio of the rate constants $\left(k_{1} / k_{2}\right)$ of the two competing reactions (determined as the ratio of ion abundances $\left.\left[\mathrm{B}_{1}+\mathrm{H}\right]^{+} /\left[\mathrm{B}_{2}+\mathrm{H}\right]^{+}\right)$is related to the difference in proton affinities $(\triangle P A)$ by eq 3 ,

$$
\ln \left(k_{1} / k_{2}\right)=\Delta \mathrm{PA} / R T
$$

where $T$ is the effective temperature of the dimer ions. The validity of eq 3 is contingent on the correctness of two assumptions, namely, that the competitive reactions (eqs 1 and 2) have similar frequency factors (entropy changes) and that the reactions have zero or very small reverse activation energies [23].

The kinetic method has been applied to the qualitative and quantitative comparison of proton affinities of a wide range of bases, including deoxynucleosides [24], deoxyribonucleosides, and their related nucleobases [25], in addition to the amino acid studies cited above. It is important to distinguish between the objectives of the present work and those of previous studies. The aim here was to establish whether the gasphase proton affinities of amino acids (both native and derivatized) are sufficiently close to suggest effective competition as sites of proton attachment in peptide ions. Major differences in relative proton affinity would suggest a sequestering of charge at a particular site in polymeric bases, whereas minor differences would imply a multiplicity of charge sites in excited precursor ions, with a consequent promotion of multiple-product ions via charge-directed fragmentations.

The majority of investigations of the decompositions of cationized heterodimeric bases have been carried out using double-focusing mass spectrometers of $\mathrm{BE}$ geometry (where $\mathrm{B}$ is the magnetic sector and $\mathrm{E}$ the electric sector) in the mass-andlyzed ion kinetic energy spectrometry (MIKES) mode. Selection of the precursor ion is made with $B$, decomposition occurs between $B$ and $E$, and analysis of the product ions is achieved by scanning $\mathrm{E}$. The mass resolution of the product ions in a MIKES analysis is poor, which precludes the comparison of two amino acids differing by $1 \mathrm{Da}$. The mass resolution of the product ions can be improved by using a $\mathrm{B} / \mathrm{E}$ linked-scan mode to examine decompositions occurring in the field-free region that precedes the first sector. In this instance, the resolution of the precursor ion is poor, which precludes the selection of a heterodimer composed of two amino acids differing by $1 \mathrm{Da}$. Unit mass resolution of both precursor and product ions can be achieved by using a BEqQ hybrid (where $q$ is the rf-only quadrupole and $Q$ the quadrupole mass filter) mass spectrometer in an $E / Q$ linked-scan mode to detect product ions formed in the second field-free region. Alternatively, decompositions 
in $\mathrm{q}$ may be examined by scanning of $\mathrm{Q}$, achieving satisfactory resolution of both precursor and product ions.

The present study used a $\mathrm{BEqQ}$ hybrid mass spectrometer to examine the decompositions of protonated and metal-cationized amino acid heterodimers. The effects of important derivatization procedures on the gas-phase properties of amino acids were investigated with reference to the implications for charge location in peptide ions.

\section{Experimental}

\section{Materials}

L-Amino acids and histidinamide were obtained from Sigma Chemical Co. (St. Louis, MO) and were used without further purification. Acetylacetone, triethylamine (Fisher Scientific Company, Fair Lawn, NJ), and acetyl chloride (J. T. Baker Chemical Co., Phillipsburg, NJ) were redistilled prior to use. 4-Vinylpyridine (Aldrich Chemical Co., Milwaukee, WI) and acetic anhydride (Sigma) were used as received. Lithium carbonate, $95 \%$ enriched with ${ }^{6} \mathrm{Li}$, was purchased from Cambridge Isotope Laboratories (Woburn, MA) and dissolved in aqueous hydrochloric acid to form ${ }^{6} \mathrm{Li}$-enriched lithium chloride.

\section{Derivatizations}

Arginine was converted to DMPO and Gly-Phe-LeuCys-Gly-His-Tyr-Arg to its DMPO analogue by following the procedure described by Thorne et al. [26]. The solid DMPO was washed with several portions of methanol.

Cysteine was converted to pyridylethylcysteine by adding a 50-fold molar excess of 4-vinylpyridine to cysteine (1 mg), which was dissolved in $100 \mu \mathrm{L}$ of 0.1 $M$ ammonium bicarbonate buffer ( $\mathrm{pH} 8.2)$, capped under nitrogen, and allowed to react for $2 \mathrm{~h}$ at $30^{\circ} \mathrm{C}$ in the dark. The reaction mixture was then lyophilized. A similar procedure was applied to the derivatization of Glu-Glu-Leu-Cys-Thr-Met-Phe-Ile-Arg.

Glycine was converted to $\mathrm{N}$-acetylglycine, as previously described by Gaskell and Keilly [27]. An equal volume of acetic anhydride was added to a solution of glycine ( $5 \mathrm{mg}$ ) in $500 \mu \mathrm{L}$ of water and was allowed to react at $20{ }^{\circ} \mathrm{C}$ overnight. The reaction mixture was dried under a stream of nitrogen.

Histidine was converted to the methyl ester by using the procedure previously described by Thorne et al. [26]. To the dry histidine (5 mg) was added $2 \mathrm{~mL}$. of $3 \mathrm{M}$ hydrochloric acid in methanol; the reaction was allowed to proceed for $2 \mathrm{~h}$ at $20^{\circ} \mathrm{C}$. The reaction mixture was then dried under a stream of nitrogen.

\section{Mass Spectrometry}

All analyses were performed using a VG ZAB SEQ hybrid mass spectrometer (VG Analytical Ltd., Man- chester, UK) with the configuration BEqQ. Ionization by $\mathrm{FAB}$ used xenon atoms with energies of $8 \mathrm{keV}$ as the primary beam. The matrix was $1 \mathrm{M}$ trichloroacetic acid in 85:15 (v/v) glycerol/water [28]. Saturated solutions of sodium chloride and lithium chloride were added to the probe $(0.2-0.5 \mu \mathrm{L})$ to form sodium and lithium adducts. Product ion spectra were acquired via the VG 11-250 data system in "multichannel analyzer" mode. Scans were of 10-15-s duration, and 10 scans were accumulated. For $Q$-scanning analyses of the heterodimers, the quadrupole mass analyzer was operated at unit mass resolution. Low-energy product ion spectra of peptides were acquired under CAD conditions with argon as collision gas at a pressure of $1.8-3.0 \times 10^{-4}$ mbar in the quadrupole collision cell (as estimated from the recorded manifold pressure and the conductance of the system). These conditions correspond to an attenuation of 50-60\% of the precursor ion intensity. The collision energy was $12-17 \mathrm{eV}$ in the laboratory frame of reference.

\section{Results and Discussion}

A series of protonated heterodimers composed of basic amino acids (arginine, histidine, and lysine) of known relative proton affinities were initially analyzed using the MIKES approach reported by Bojesen [19, 28]. Thus, the protonated heterodimers of interest, formed by FAB ionization, were selected using the magnetic sector (B) of the hybrid instrument, and the product ions resulting from spontaneous decompositions occurring in the second field-free region (between $B$ and E) were analyzed by scanning $E$. The relative heights of the peaks displayed in the MIKE spectra confirmed the expected ranking of gas-phase proton affinities: arginine $>$ histidine $>$ lysine. During the MIKES anal$y s$ s of the protonated dimer of lysine and histidine, both protonated amino acids were clearly detected as metastable product ions, indicating competitive proton affinities for the two amino acids. The relative heights of the peaks observed were in good agreement with Bojesen's results [28].

A disadvantage of MIKES analyses for some applications is the poor mass resolution of the product ions, which hinders the study of protonated heterodimers consisting of components closely separated in mass. A series of heterodimers composed of basic amino acids was also analyzed using the hybrid instrument with $Q$ scaruing of product ions formed in $q$. Full-scan product ion spectra of the protonated heterodimer. [Arg . His $+\mathrm{H}]^{+}$, obtained by scanning $\mathrm{E}$ (MIKES analysis) and by scarning $Q$ are presented in Figure 1a and b, respectively. Both spectra indicated that the proton was retained exchusively on the arginine because no protonated histidine was detected. A superior signalto-noise ratio was observed in the $Q$-scan spectrum, consistent with a higher yield of product ions from this extended time-scale experiment. The MIKE spectrum 


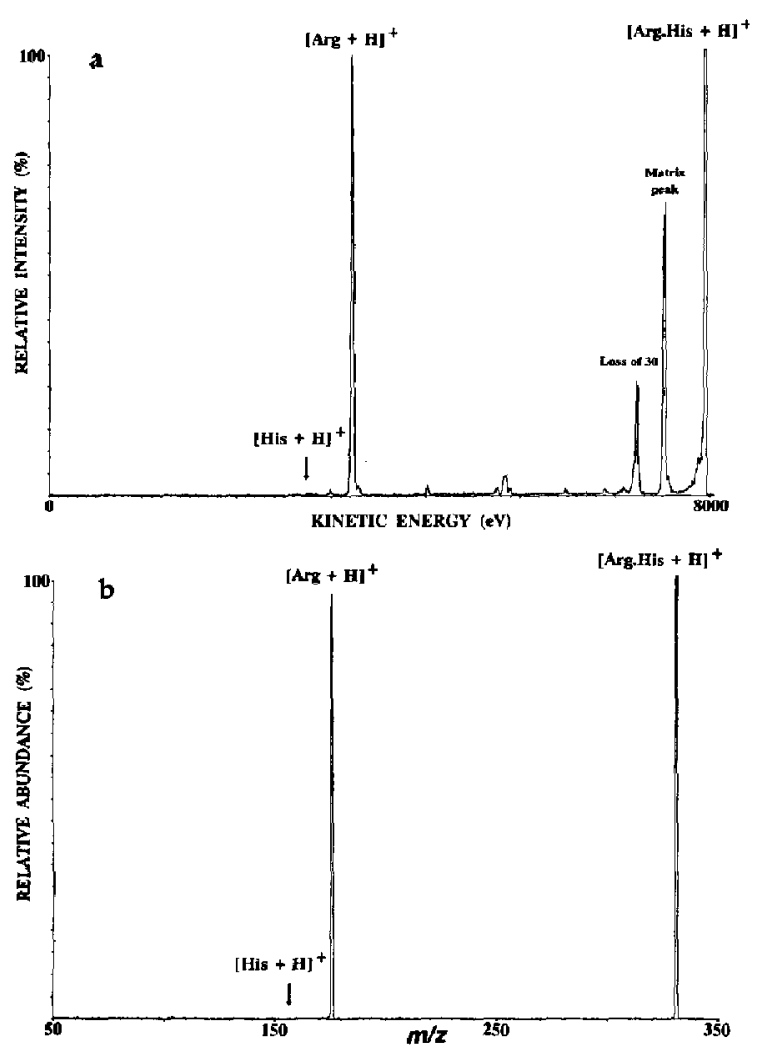

Figure 1. Metastable product ion spectra of the protonated heterodimer $\left[\mathrm{Arg} \cdot \mathrm{His}+\mathrm{H}^{+}\right.$obtained by (a) MIKES analysis and (b) scanning of $Q$.

(Figure 1a) showed several product ions apparently derived by loss of small neutral fragments from the selected precursor. These signals included a contribution from matrix-derived precursor ions (as judged from analysis of matrix alone). There are three possible explanations for this observation, which contrasts with the absence of these signals in the equivalent Q-scan (Figure 1b). One possibility is that a more heterogeneous population of precursor ions is selected in the MIKES analysis than in the experiment where precursor ions are transmitted through B and E. Another possibility is that precursor ions present in the second ficld free region include a proportion of sufficiently high internal energy that relatively high-energy decomposition channels are accessed. These precursor ions are of insufficient stability to survive the extended time required for transmission to q. The last possibility is that the additional signals observed in the MIKE spectrum are associated with decompositions occurring in the first field-free region (preceding B). Such products are not transmitted to the point of double focus and are therefore excluded from the spectrum obtained by $\mathrm{Q}$-scanning.

Table 1 shows relative abundance data from analyses of the decompositions of several protonated het-
Table 1. Decompositions of protonated dimers of native and derivatized amino acids

\begin{tabular}{|c|c|c|c|c|}
\hline \multirow[b]{2}{*}{ Protonated dimer ${ }^{a}$} & \multirow[b]{2}{*}{$\rightarrow$} & \multirow[b]{2}{*}{ Product ions } & \multicolumn{2}{|c|}{ Relative peak heights } \\
\hline & & & Q-scan & MIKES $^{\mathrm{C}}$ \\
\hline \multirow[t]{2}{*}{$\overline{\mathrm{LHis} \cdot \mathrm{Lys}+\mathrm{H}]^{+}}$} & $\rightarrow$ & {$[\mathrm{His}+\mathrm{H}]^{+}$} & 100 & $100(100)$ \\
\hline & & {$[\mathrm{L} y \mathbf{s}+\mathbf{H}]^{+}$} & 23 & $13(14)$ \\
\hline \multirow[t]{2}{*}[\text{Lys}\cdot\text{Cys-PE}+H]{$^{+}$} & $\rightarrow$ & {$\left[L y s+\mathbf{H}^{+}\right.$} & 100 & $88(100)$ \\
\hline & & {$\left[\right.$ Cys-PE $+\mathrm{H}^{+}$} & 38 & $100(74)$ \\
\hline \multirow{2}{*}[\mathrm{His}\cdot\text{Cys-PE}+\mathrm{H}]{$^{+}$} & $\rightarrow$ & {$\left[\mathrm{His}+\mathrm{HI}^{+}\right.$} & 100 & $100(100)$ \\
\hline & & {$\left[\right.$ Cys-PE $+\mathrm{H}^{+}$} & 10 & $14(10)$ \\
\hline \multirow[t]{2}{*}[\mathrm{Arg}-\mathrm{DMPO}+\mathrm{H}]{$^{+}$} & $\rightarrow$ & {$\left[\right.$ Arg $+\mathrm{H}^{+}$} & 100 & 一 \\
\hline & & {$[\mathrm{OMPO}+\mathrm{H}]^{+}$} & 2 & \\
\hline \multirow[t]{2}{*}{ 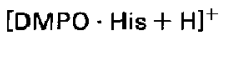 } & $\rightarrow$ & ${\text { [DMPO }+\mathrm{H}^{+}}^{+}$ & 100 & - \\
\hline & & {$\left[\mathrm{H}_{\mathrm{IS}}+\mathrm{H}\right]^{\prime}$} & 1 & \\
\hline \multirow{2}{*}[\text{Cys-Cys-PE}+\mathrm{H}]{$^{+}$} & $\rightarrow$ & {$[\mathrm{Cys}+\mathrm{H}]^{+}$} & 1 & - \\
\hline & & {$\left[\right.$ Cys-PE $+\mathrm{H}^{+}$} & 100 & \\
\hline \multirow[t]{2}{*}[\mathrm{Gly}\cdot\mathrm{Ac}-\mathrm{Gly}+\mathrm{H}]{$^{+}$} & $\rightarrow$ & [Gly + H] $^{+}$ & 50 & - \\
\hline & & {$[\mathrm{Ac}-\mathrm{Gly}+\mathrm{H}]^{+}$} & 100 & \\
\hline
\end{tabular}

${ }^{a}$ Abbreviations are the standard three-letter cades for the amino acids. with the following exceptions: $C y s-P E$, pyridylethyl cysteine; DMPO, dimethylpyrimidylorn ithine; Ac-Gly, $\mathrm{N}$-acetyl glycine.

${ }^{b}$ Spontaneous decomposition of the heterodimers in the rf-only quadrupole and analysis of the product ivis by scaming of $Q$.

"Spontaneous decomposition of the heterodimer's in the second field-free region and analysis of the product ions by scanning of $E$. Values in parentheses are corrected on the assumption that sensitivity of detection is inversely related to mass $\left([\mathrm{His}+\mathrm{H}]^{+}, m / z 156\right.$; $\left[\right.$ Lys $+\mathrm{H}^{+}, m / 2$ 147; [Cys-PE $+\mathrm{H}^{+}, m / z$ 227).

erodimers, including several examples that were examined using both the MIKES and Q-scanning procedures. As is generally observed for Q-scanning of product ion spectra, optimization of the ramp governing the float potential of $Q$ as a function of mass (thus determining the kinetic energy of ions introduced to the mass filter) was found to be critical to the achievement of reproducible data. When using the MIKES approach, optimization of the double-focusing settings for the precursor ion signal influenced the reproducibility of the peak height ratios of the product ions. Tuning of the instrument was thus important for the reproducibility obtained by both techniques. In practice, however, somewhat better reproducibility was observed for the Q-scan data. Coefficients of variation of 1-10\% were calculated for the relative heights of the product ions when the peak heights differed by a factor of 10 or less.

The determination of the decompositions of the protonated dimers formed by combinations of histidine, lysine, and pyridylethylcysteine (Cys- $\mathrm{PE}$, a cysteine derivative discussed below) enabled assessments of the internal consistencies of the MIKES and Q-scanning methods (Table 1 ). The results of analyses of the $[\mathrm{His} \cdot \mathrm{Lys}+\mathrm{H}]^{+}$and $[\mathrm{His} \cdot \mathrm{Cys}-\mathrm{PE}+\mathrm{H}]^{+}$dimers, for example, predicted a relative abundance of $9 \%$ for $[\mathrm{Cys}-\mathrm{PE}+\mathrm{H}]^{+}$as a product of [Lys $\left.\cdot \mathrm{Cys}-\mathrm{PE}+\mathrm{H}\right]^{+}$; a value of $10 \pm 1 \%$ SD was obtained experimentally. Similar internal consistency was observed for the MIKES data. 
Although the quantitative estimation of proton affinities was not the principal focus of this work, a determination of this kind was made to enable a further comparison of the MIKES and Q-scan methods. It was assumed (as has been done previously [23]) that the sensitivities of detection of product ions in the MIKES analyses were inversely proportional to ion mass. The relative intensities of product ion signals were accordingly corrected in this manner (Table 1). For the Q-scan analyses, the relative efficiencies of transmission through $Q$ and subsequent detection were determined tor protonated or metal-cationized amino acids derived from heterodimers. The instrument was tuned for the analysis of the products of decomposition of the cationized heterodimer in $\mathrm{q}$. The intensities of the signals for each of the source-formed protonated or metal-cationized amino acids were recorded at the detector at the point of double focus. Each ion was then selected to be transmitted through the quadrupole assembly, and the intensity of the signal was recorded at the final detector (following Q). Similar transmissions through $Q$ were estimated for the two cationized amino acids contributing to each of the heterodimers, histidine/lysine (differing in mass by $9 \mathrm{Da}$ ) and histidine/DMPO (differing by $83 \mathrm{Da}$ ). This indicated that there was no significant mass discrimination observed in $Q$ in the mass range studied.

When relative abundance data obtained using the MIKES method were corrected (as described above) for estimated relative sensitivities of detection (Table 1), the ranking of proton affinities evident from the MIKES and $\mathrm{Q}$-scan data ( $\mathrm{His}>$ Lys $>$ Cys-PE) was the same. The figures for the relative abundances of protonated monomers derived from a given protonated heterodimer are not, however, expected to be the same for the two experiments. Reference to eq 3 indicates that the difference in activation energies (corresponding to the difference in proton affinities of the amino acid monomers $)$ is related to $\ln \left(k_{1} / k_{2}\right)$ and to the effective temperature of the dimeric precursor [23]. The time scales of the MIKES and Q-scan experiments indicate that the latter samples a precursor population of greater "age" and consequently of lower effective temperature.

Thus, assessment of the quantitative agreement between the MTKES and Q-scan methods requires a comparison of derived proton affinity values. Literature values [29] for the proton affinities of histidine (231.9 $\mathrm{kcal} / \mathrm{mol})$ and lysine $(230.3 \mathrm{kcal} / \mathrm{mol})$ were used to determine in each case the linear relationship (eq 3) between proton affinity and the $\log$ of the ratio of ion abundances. This enabled estimates of the proton affinity of the pyridylethyl derivalive of cysleine on the basis of two sets of relative abundance data (MIKES and Q-scan) shown in Table 1 (incorporating a correction for the relative detection efficiencies in the MIKES data). In this manner, the proton affinity for pyridylethyl cysteine was estimated to be $229.3 \mathrm{kcal} / \mathrm{mol}$ from the Q-scan data and $230.0 \mathrm{kcal} / \mathrm{mol}$ from the
MIKES data. Experimental uncertainties were estimated as $\pm 0.2 \mathrm{kcal} / \mathrm{mol}$ (not taking into account the uncertainties of the literature values of the proton affinities of histidine and lysine). The apparent minor discrepancy between the MIKES and Q-scan data may result from an imperfect correction of the MIKES data for relative sensitivities of detection or may reflect a limitation in the validity of the assumptions underlying the kinetic method; our data do not permit us to distinguish between these possibilities.

For the principal purpose of the present study, however, the significant conclusion from both the Qscan and the MIKES data is that the proton affinities are ranked His $>$ Lys $>$ Cys-PE but that the affinities are sufficiently similar that significant competition for proton attachment will occur in activated peptide ions incorporating more than one of these amino acid residues. Q-scanning of the products of decompositions in the rf-only quadrupole was used for the remaining experiments in the present study.

\section{Effect of Derivatization on the Gas-Phase Proton Affinity of Amino Acids}

The gas-phase proton affinity of pyridylethylcysteine was discussed above. The conversion of cysteine to pyridylethylcysteine by reaction with 4-vinylpyridine (Scheme 1) is frequently used for non-mass spectrometric purposes to protect cysteine residues (including those derived by reduction of disulfide bridges) in proteins prior to the application of sequencing procedures. The possible mass spectrometric utility of this derivative results from the introduction of a basic site,

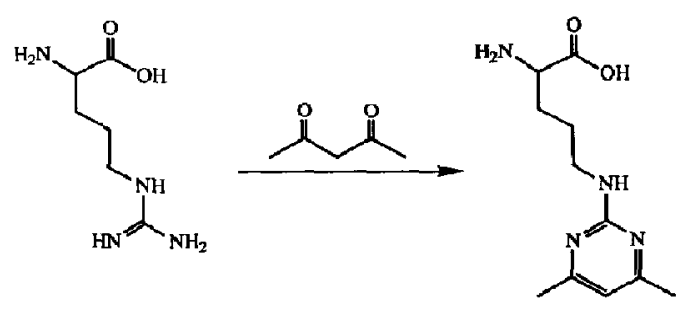

Arginine

Dimethylpyrimidylomithine<smiles>NC(CS)C(=O)O</smiles>

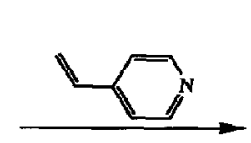

Cysteine<smiles>N[C@@H](CSCCc1ccncc1)C(=O)O</smiles>

Pyridylethylcysteine

Scheme I 
which may result in the observation of alternative fragment ions associated with retention of the charge at this position. The analysis of the protonated dimer $[\text { Cys } \cdot \mathrm{Cys}-\mathrm{PE}+\mathrm{H}]^{+}$showed, as expected, that the pyridylethyl derivative of cysteine had a much higher proton affinity than cysteine itself (Table 1). The effect of pyridylethylation on the fragmentation of a protonated cysteine-containing peptide was examined. As previously reported [7], the product ion spectrum obtained by low-energy CAD of protonated Glu-GluLeu-Cys-Thr-Met-Phe-Ile-Arg indicated a poor yield of fragment ions, attributable (it was postulated [7]) to predominant charge location on the C-terminal arginine side chain. Conversion of the cysteine to the pyridylethyl derivative favored the formation of a partial series of $\mathbf{B}_{n}$ ions that included the pyridylethylcysteine residue (Figure 2). Evidently, cleavage of peptide bonds resulted in charge retention on either terminal fragment in those instances where the $\mathrm{N}$-terminal portion retained the basic pyridylethyl group.

A second derivatization studied was that of arginine to DMPO by reaction with acetylacetone, converting the guanidino group to a pyrimidyl ring (Scheme I). The relative proportions of protonated monomers as products of spontaneous decomposition of the protonated heterodimer $[\mathrm{Arg} \cdot \mathrm{DMPO}+\mathrm{H}]^{+}$are given in Table 1 . The data indicated the expected reduction in gas-phase proton affinity accompanying the Arg to DMPO conversion. Protonated DMPO was observed at a relative abundance only $2 \%$ of that of protonated arginine. Nevertheless, the proton affinity of DMPO substantially exceeds that of histidine (Table 1). Figure 3 compares the product ion spectra of protonated GlyPhe-Leu-Cys-Gly-His-Tyr-Arg and Gly-Phe-Leu-CysGly-His-Tyr-DMPO recorded under similar conditions of low-energy collisional activation. The $Y_{1}^{\prime \prime}$ ion is of reduced prevalence in the spectrum of the DMPO analogue, but the general similarity of the two spectra

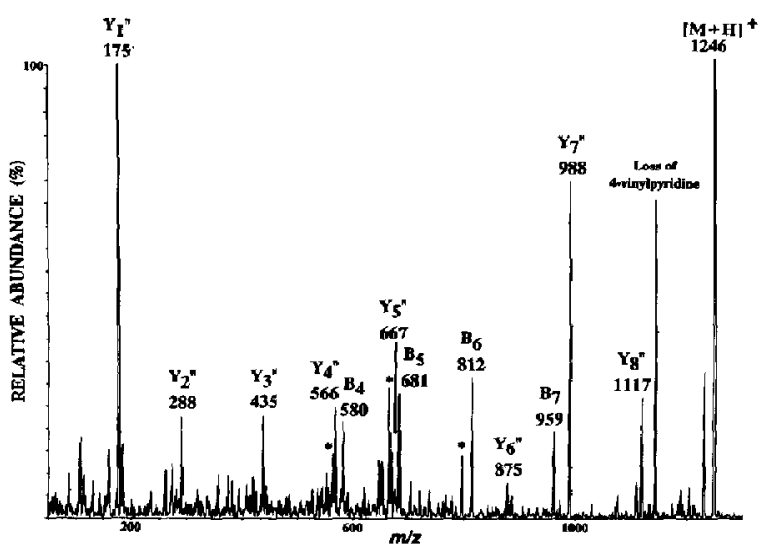

Figure 2. Low-energy CAD product ion spectrum of the $I M+$ $\mathrm{HJ}^{+}$ion of Glu-Glu-Leu-Cys-Thr-Met-Phe-Ile-Arg as the pyridylethyl derivative; ${ }^{*}$ indicates the loss of $18 \mathrm{Da}\left(\mathrm{H}_{2} \mathrm{O}\right)$ from the $\mathrm{B}$ ions.

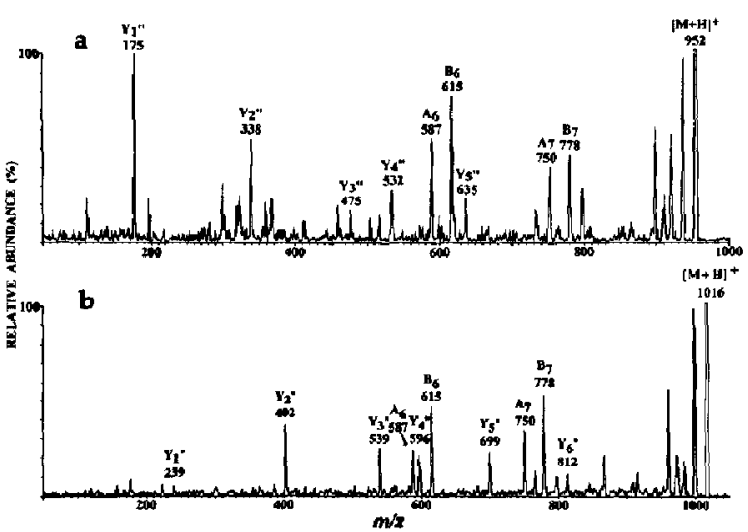

Figure 3. Low-energy CAD product ion spectra of the $[\mathrm{M}+\mathrm{H}]^{+}$ ions of (a) Gly-Phe-Leu-Cys-Gly-His-Tyr-Arg and (b) Gly-PheLeu-Cys-Gly-His-Tyr-DMPO.

is consistent with the $\mathrm{C}$-terminal residue remaining the most basic site. In other circumstances, where the conversion of an arginine to a DMPO residue has been shown markedly to affect fragmentation patterns [26], steric factors as well as changes in proton affinity may be influential.

Also examined were the products of decomposition of the protonated heterodimer composed of glycine and $N$-acetylglycine (which lack side chains). The results (Table 1) indicate effective competition for retention of the proton, with the acetylated derivative possessing the greater proton affinity. The observation of somewhat greater proton affinity for the amide bond compared with the primary amine group (situated alpha to a carboxyl moiety) is relevant to the consideration of charge location in protonated peptides. These findings are consistent with the proposition of Hunt et al. [6] that internal amide linkages in peptide ions are preferential sites of charge localization compared with the amino terminus.

In a recent discussion, Bursey and co-workers [30] also argued that internal amide bonds may be competitive with the $\mathrm{N}$-terminal amino group as the site of protonation. They suggest on the basis of calculated proton affinities, however, that the N-terminal amino group represents the "intrinsically most basic site" in peptides composed of amino acid residucs lacking basic side chains. Amide bonds may become the preferred sites of protonation (assuming thermodynamic rather than kinetic control) by virtue of ion-dipole solvation and extensive hydrogen bonding $[6,14]$. The common conclusion from the present work and the discussion of Bursey and co-workers is that differences in proton affinities between internal amide bonds and the $\mathrm{N}$-terminal amine are expected to be small, so that a population of protonated peptides (not incorporating strongly basic side chains) is likely to be heterogeneous with respect to the site of protonation. Expressed differently, the energy barriers to interconver- 
sion of protonated forms, differing in the site of protonation, are expected to be sufficiently low that the rationalization of fragmentation processes may plausibly invoke one of a number of possible protonated precursors.

\section{Decompositions of Metal-Cationized Amino Acid Heterodimers}

The application of the kinetic method to the determination of relative metal cation affinitics of amino acids has also been reported [31]. Spectra recorded for the decompositions of the protonated and metal-cationized dimer of histidine and DMPO are presented in Figure 4. Once again, the quantitative determination of cation affinities was not the purpose of the present work. Inspection of the spectra in Figure 4, however, provides evidence for the particularly avid binding of metal cations to histidine. Russell et al. [14] suggested the strong binding of sodium cation to the histidine residue of a tripeptide and postulated a bidentate interaction with the imidazole ring and the $\mathrm{N}$-terminal amino group. Equivalent chelated structures for lithiated peptide $A_{n}$ fragment ions were suggested by Gross and co-workers [12] in a study of the CAD of lithiated histidine-containing peptides. The stable conformation resulting from the bidentate interaction with the cation favored the cleavage of the peptide bond
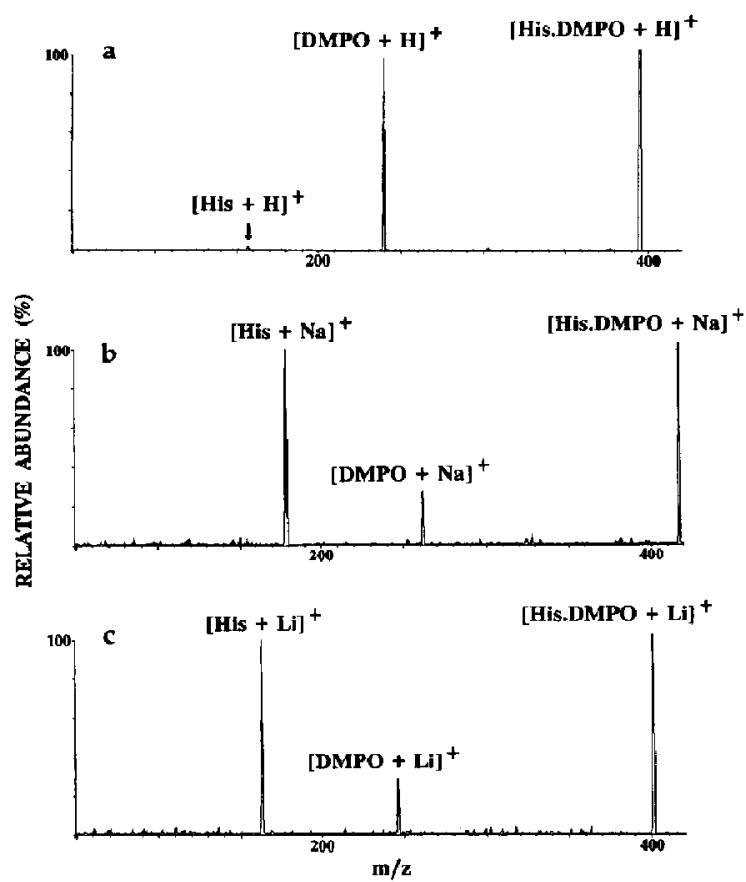

Figure 4. Product ion spectra of the spontaneous decomposition in $\mathrm{q}$ of the heterodimer composed of histidine and DMPO that was cationized with a (a) proton, (b) sodium ion, and (c) lithium ion, incorporating the carboxyl group of the histidine residue.

The analysis of lithiated heterodimers presented two additional points worthy of note. The first was the presence of protonated arginine in the product ion spectra of lithiated dimers containing arginine. The analysis of $\left[\mathrm{Arg} \cdot \mathrm{DMPO}+\mathrm{Li}^{+}\right.$, for example, gave a signal corresponding to $\left[\mathrm{Arg}+\mathrm{H}^{+}\right.$, with a relative abundance of $7 \%$ of that corresponding to $[\mathrm{Arg}+\mathrm{Li}]^{+}$. Evidently, a proton is abstracted from the DMPO moiety, yielding $\left[\mathrm{Arg}+\mathrm{H}^{+}\right.$and (presumably) a [DMPO $+\mathrm{Li}-\mathrm{H}]$ neutral species. This observation implies an interaction between the amino acid components of the cationized dimer more complex than suggested by a structure of the form (Arg $\cdots$ Cat $\cdots$ DMPO) $)^{+}$, thus casting doubt, in this instance, on the validity of the assumptions underlying eq $3[23,32]$. Accordingly, these observations suggest caution in translating the relative abundances of the cationized monomer decomposition products into metal-cation affinities of the amino acids.

A second additional observation of interest concerned the analysis of lithiated heterodimers containing histidine and lysine, histidinamide $\left(\mathrm{His}-\mathrm{NH}_{2}\right)$ or histidine methyl ester (His-Me). Preferential retention of the metal cation by histidine following decomposition of the heterodimers with histidinamide or histidine methyl ester implied the involvement of the carboxyl group in mctal binding. Each heterodimer generated a product ion spectrum displaying a peak at $m / z 168$ with a relative abundance of $1-10 \%$ of the strongest lithiated single amino acid peak. The product ion spectrum of the lithiated heterodimer [His - Lys + $\mathrm{Li}^{+}$is presented in Figure 5. When a ${ }^{6} \mathrm{Li}$ salt was used for generation of the lithiated helerodimer, the peak corresponding to $\left[\mathrm{His}+\mathrm{Li}^{+}\right.$was shifted from $\mathrm{m} / \mathrm{z}$ 162 to 161 , and $m / z 168$ was shifted to 166 . The latter shift demonstrated the incorporation of two lithiums, consistent with the assignment $[\mathrm{His}+2 \mathrm{Li}-\mathrm{H}]^{+}$. It

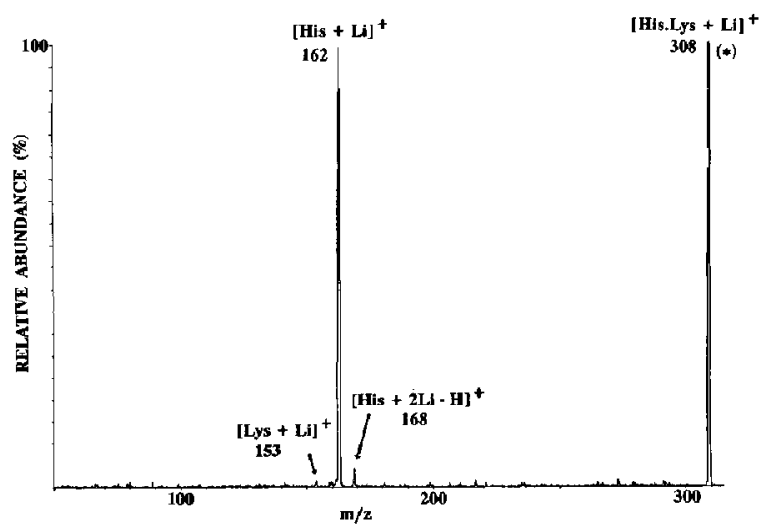

Figure 5. Product ion spectrum of the spontaneous decomposition in $\mathrm{q}$ of the lithiated heterodimer composed of histidine and lysine; * the precursor ion also contains the dilithiated tetramer $[\text { His } \cdot \text { Lys }+\mathrm{Li}]_{2}^{2+}$ (see text). 
was concluded that this product ion originated from decomposition of doubly charged dilithiated heterotetramers (e.g., [His $\cdot$ Lys $+\mathrm{Li}]_{2}^{2+}$, [His $\cdot$ His-Me $+\mathrm{Li}_{2}^{2+}$ and $\left[\mathrm{His} \cdot \mathrm{His}-\mathrm{NH}_{2}+\mathrm{Li}_{2}^{2+}\right.$ ), which have the same mass-to-charge ratio value as the monolithiated singly charged dimers. It was noted that the relative abundance of $[\mathrm{His}+2 \mathrm{Li}-\mathrm{H}]^{+}$increased during the course of an analysis, presumably due to an increased ratio of lithium salt to analyte. Addition of further lithium salt to the sample promoted the formation of the $m / z 168$ product ion.

Evidence for the formation of a dicationized tetramer was obtained only for lithiated species. Histidine was the only amino acid in this study that was observed to retain two lithium ions. Neither histidine methyl ester nor histidinamide exhibited this behavior, indicating that the carboxyl group is required for the attachment of the second lithium ion.

\section{Conclusions}

The decompositions of protonated heterodimers of amino acids were examined as predictors of charge location in peptide ions. Analyses using a hybrid instrument of BEqQ geometry permitted the comparison of spectra corresponding to decompositions in the second field-free region (MIKES analyses) and in the rf-only quadrupole (with scanning of $Q$ ). The $Q$-scan procedure was preferred on the basis of signal intensity and reproducibility, but the two methods gave the same ranking of proton affinities. The equivalence of the procedures was further established by comparing the derived proton affinity values for pyridylethylcysteine, although a minor discrepancy was apparent.

The effect of derivatization procedures that achieve useful modifications of peptide fragmentation behavior was of particular interest. Thus, for example, the conversion of cysteine to pyridylethylcysteine increases the relative gas-phase proton affinity of the amino acid. A similar derivatization applied to a peptide was shown to promote the observation of fragments that retain the charge on the new basic site. When glycine (which lacks a side chain) was converted to the $N$-acetyl derivative, the proton affinity was increased, suggesting, in the context of peptide analyses, that the peptide bond is competitive with the $\mathrm{N}$-terminal amino group as a site of charge location. It is clear, however, as others have indicated $[6,30]$, that the proton affinities of particular sites in peptides are influenced by both short- and long-range intraionic interactions. Wu and Fenselau [33] have suggested that the observed increase in proton affinity with increasing chain length of polyglycines is attributable to multiple functional group interactions. Bursey and co-workers $[30,34]$ have calculated the proton affinities of some basic sites in peptides, taking into account the influence of proximal functional groups. They have suggested the modification of these "intrinsic" values by ion-dipole and hydrogen bonding interactions in pep- tides. Our previous work [7] has provided a specific example of the apparent attenuation of the basicity of the arginine side chain via long-range interaction with an acidic group. Nevertheless, the observed decompositions of protonated heterodimers of amino acids may be considered as a guide to the properties of the equivalent amino acid residues in peptides. In peptides composed of amino acids of similar cation affinities, it may be postulated that the ion population is heterogeneous with respect to the site of charge, with consequent promotion of multiple fragmentation routes.

\section{Acknowledgments}

This work was supported by the National Institutes of Ilealth (GM 48267). The constructive comments of an anonymous reviewer are gratefully acknowledged.

\section{References}

1. Johnson, R. S.; Martin, S, A,; Biemann, K. Int. J. Mass Spectrom. Ion Processes 1988, 86, 137-154.

2. Vath, J. E.; Biemann, K. Int. /. Mass Spectrom. Ion Processes $1990,700,287-299$

3. Wagner, D. S.; Salari, A.; Gage, D. A.; Leykam, J.; Fetter, J.; Hollingsworth, R.; Watson, J. T. Biol. Mass Spectrom. 1991, 20, 419-425.

4. Watson, J. T.; Wagner, D. S.; Chang, Y.-S.; Strahler, J.; Hanash, S.; Gage, D. A. Int. J. Mass Spectrom. Ion Processes 1991, 111, 191.

5. Roepstorff, P,; Fohlman, J. Bioned. Mass Spectrom. 1984, 11, 601.

6. Hunt, D. F; Yates, J. R, III; Shabanowitz, J; Winston, S.; Hauer, C. R. Proc. Nat!. Acad. Sci. USA 1986, 83, 6233-6237.

7. Burlet, O; Yang, C.-Y.; Gaskell, S. J. J. Am. Soc. Mass Spectrom. 1992, 3, 337-344.

8. Falick, A. M.; Maltby, D. A. Anal. Biochem. 1989, 182, 165-169.

9. Mathews, W. R.; Runge, T. A.; Haroldsen, P. E.; Gaskell, S. J. Rapid Commun. Mass Spectrom. 1989, 3, 314-319.

10. Morris, H. R.; Panico, M.; Barber, M.; Bordoli, R. S.; Sedgwick, R. D. Biochem. Biophys. Res. Commun. 1981, 101, 623-631.

11. Grese, R. P.; Gross, M. L. J. Am. Chem. Soc. 1990, 112, 5098-5104.

12. Grese, R. P.; Cerny, R. L.; Gross, M. L. J. Am. Chem. Soc. $1989,111,2835-2842$.

13. Leary, J. A.; Zhou, Z; Ogden, S. A.: Williams, T. D. I. Am. Soc. Mass Spectrom. 1990, 1, 473-480.

14. Russell, D. H.; McGlohon, E. S.; Mallis, L. M. Anal. Chem. 1988, 60, 1818-1824.

15. Mallis, L. M.; Russell, D. H. Anal. Chem. 1986, 58, 1076-1080.

16. Tang, K.; Ens, W.; Standing, K. G.; Westmore, J. B. Anal. Chem. 1988, 60, 1791-1799.

17. Teesch, L. M.; Adams, J. J. Am. Chem. Soc. 1991, 113, 812-820.

18. Teesch, L. M.; Orlando, R. C.; Adams, J. J. Am. Chem. Soc. $1991,113,3668-3675$.

19. Bojesen, G. I. Am. Chem. Soc. 1987, 109, 5558-5560.

20. Wu, Z.; Fenselau, C. Rapid Commun. Mass Spectrom. 1992, 6, $403-405$.

21. Isa, K.; Omote, T.; Amaya, M. Org. Mnss Spectrom. 1990, 25, $620-628$. 
22. Cooks, R. G.; Kruger, T. L. I. Am. Chem. Soc. 1977, 99, 1279-1281.

23. Mcluckey, S. A.; Cameron, D.; Cooks, R. G. J. Am. Chem. Soc. 1981, 103, 1313-1317.

24. Liguori, A.; Sindona, G.: Uccella, N. Ado. Mass Spectrom. 1989, 11A, 950.

25. Greco, F.; Liguori, A.; Sindona, G.; Uccella, N. J. Am. Chem. Soc. 1990, 112, 9092-9096.

26. Thorne, G. C.; Ballard, K. D.; Gaskell, S. J. I. Am. Soc. Mass Spectrom. 1990, 1, 249257.

27. Gaskell, S. J.; Reilly. M. H. Rapid Commun. Mass Spectrom. 1988, 2, 188-191.

28. Bojesen, G. I. Chem. Soc. Chem. Commun. 1986, 244-245.
29. Lias, S. G.; Liebman, J. F.; Levin, R. D. J. Phys. Chem. Ref. Data 1984, 13, 695-778.

30. Yeh, R. W.; Grimley, J. M.; Bursey, M. M. Biol. Mass Spectrom. 1991, 20, 443-450.

31. Breindahl, T.; Bojesen, G. Proceedings of the 12th International Mass Spectrometry Conference, Amsterdam, WeA-B47.

32. McLuckey, S. A.; Schuen, A. E.; Cooks, R. G. J. Am. Chem. Soc. 1982, 104, 848-850.

33. Wu, Z; Fenselau, C. J. Am. Soc. Mass Spectrom. 1992, 3, 863-866.

34. Schwartz, B. L.; Bursey, M. M. Biol. Mass Spectrom. 1992, 21, 92-96. 